\title{
Prevention of Diabetic Complications by Walnut Leaf Extract via Changing Aldose Reductase Activity: An Experiment in Diabetic Rat Tissue
}

\author{
Zahra Abbasi, ${ }^{1}$ Gholamali Jelodar ${ }^{\mathbb{D}},{ }^{1}$ and Bita Geramizadeh ${ }^{2}$ \\ ${ }^{1}$ Department of Physiology, School of Veterinary Medicine, Shiraz University, Shiraz 71345, Iran \\ ${ }^{2}$ Department of Pathology, Shiraz University of Medical Science, Shiraz, Iran \\ Correspondence should be addressed to Gholamali Jelodar; jelodar@shirazu.ac.ir
}

Received 17 June 2020; Revised 26 July 2020; Accepted 31 July 2020; Published 17 August 2020

Academic Editor: Almudena Gómez-Hernández

Copyright (C) 2020 Zahra Abbasi et al. This is an open access article distributed under the Creative Commons Attribution License, which permits unrestricted use, distribution, and reproduction in any medium, provided the original work is properly cited.

\begin{abstract}
Background. Increased activity of aldose reductase (AR) is one of the mechanisms involved in the development of diabetic complications. Inhibiting AR can be a target to prevent diabetes complications. This study is aimed at evaluating the effect of cyclohexane $(\mathrm{CH})$ and ethanol extracts (ET) of walnut leaves on AR activity in the lens and testis of diabetic rats. Methods. Fifty-six male rats classified into seven groups as control and treatment groups and treated for 30 days. The treatment groups were treated with different concentrations of ET and $\mathrm{CH}$. The diabetic control (DC) group was exposed to streptozotocin. AR activity was measured in the lens and testis. The expression of AR in the testis was evaluated by the immunohistochemistry method. Results. Both extracts significantly reduced the AR activity (ng/mg of tissue protein) in the testis $(0.034 \pm 0.004,0.038$ \pm 0.010 , and $0.040 \pm 0.007$ in the treatment groups vs. $0.075 \pm 0.007$ in the DC group) and lens $(1.66 \pm 0.09,2.70 \pm 0.47$, and $1.77 \pm 0.20$ in the treatment groups vs. $6.29 \pm 0.48$ in the DC group) of the treatment group compared to those of the DC group $(P<0.05)$. AR expression in the testes of the treatment groups was decreased compared with that of the DC group $(P<0.0001)$. Conclusion. Walnut leaf extracts can reduce the activity and localization of AR in the testes and its activity in the lens of diabetic rats.
\end{abstract}

\section{Background}

Diabetes mellitus is one of the most important endocrine and metabolic disorders and its prevalence increasing globally and expected to rise to approximately 300 million people worldwide until 2025 [1]. Prolonged chronic hyperglycemia is the main cause of complications in diabetes. Male reproductive dysfunction and cataract are important complications of diabetes mellitus [2]. The development of these complications was suggested to be through increasing the activity of aldose reductase (AR) in the polyol pathway (PPW), advanced glycation end products (AGEs), overexpression of AGE receptor, protein kinase $\mathrm{C}$ isoform activation, glucosamine pathway activation, and excessive oxidative stress. These conditions can cause important complications such as neuropathy, nephropathy, retinopathy, and cataracts [3]. Typically, less than $3 \%$ of serum glucose enters the PPW. However, at high concentrations of glucose, more than $30 \%$ of glucose enters this pathway and leads to the accumulation of sorbitol in tissues [4]. Increased oxidative stress after hyperglycemia is caused mainly through autoxidation glycosylation, AGE formation, and increasing polyol pathway activity [5].

Hyperglycemia can evoke a mitochondrial overload in tissues with a high rate of energy metabolism, which results in increased mitochondrial respiratory chain activity and oxidative stress [6].

Hyperglycemia-induced oxidative stress has been proposed as an important factor affecting reproductive function by excessive generation of reactive oxygen species (ROS) that interfere with the ability of the body to neutralize free radicals by either enzymatic or nonenzymatic antioxidants [7]. However, the biochemical structures of the cell membrane impair as ROS possess high affinity polyunsaturated fatty acids [8]. 
ROS generated in hyperglycemic condition or hypoxic conditions such as varicocele leads to DNA damage, endothelial injury, oxidative stress, apoptosis, and necrosis of germinal cells [9]. Treatment of varicocele-induced rats with hesperidin was reported to improve testicular damage through its antioxidant properties [10].

Lens epithelial cells are the main site of metabolic activity of the lens, and their oxidative damage has an important role in cataract formation [11]. The lens is rich in mitochondria, and only the mature and differentiating fibers as well as epithelium lack mitochondria [12]. Superficial fiber cells and the mitochondria of lens epithelial cells consume $90 \%$ of the lens oxygen and are the main sources of endogenous ROS [13, 14]. It is estimated that up to $1 \%$ to $5 \%$ of oxygen consumed by the lens mitochondria is converted to ROS [15].

Experimental overexpression of AR in the lens of diabetic mice accelerates the development of cataracts [16, 17], whereas knockdown of the $\mathrm{AR}$ in rats protects the lens from opacification ex vivo [18]. Previous studies showed that the administration of an AR inhibitor delays the development of cataracts in diabetic dogs and mice [19]. Moreover, several studies have shown that there is a strong relationship between increased AR activity and the risk of other chronic diabetic complications such as neuropathy and retinopathy [20-23].

A decrease in enzymes involved in reducing ROS in the testis tissue of diabetic rats has been reported [24]. Oxidative stress causes cell damage through mechanisms such as destruction in the endothelium of tubule and apoptosis in the testicular germ cell, lipid peroxidation, and DNA and protein oxidative damage in the tissues [25].

Walnut leaves are a good source of antioxidants such as phenol, which can play a crucial role in preventing diseases that involve free radicals as their pathogenesis [26].

Various beneficial effects of the walnut leaf (Juglans regia L.) as an antioxidant, anti-inflammatory, and anticancer have already been reported in mice [27-29]. Studies have shown that the use of walnut leaves in the form of aqueousalcoholic extract, alcohol, cyclohexane, and powder decreases blood glucose level in alloxan- or streptozotocin- (STZ-) induced diabetic rats [30-32]. Oral administration of cyclohexane, ether, and ethanol extracts of walnut leaves was reported to decrease the blood glucose, serum triglyceride, cholesterol, and blood urea nitrogen in rats [32]. Improvement of the activity of sorbitol dehydrogenase in diabetic rats was also reported following treatment with walnut leaf extract [20]. The in vivo antioxidant effects of a polyphenol-rich walnut extract in diabetic animals have frequently been reported $[33,34]$.

In this study, we aimed to investigate the effect of oral administration of different doses of cyclohexane and ethanol extracts of the walnut leaf on the distribution and activity of aldose reductase in the testis and lens of diabetic male rats.

\section{Methods}

2.1. Plant Materials and Extraction. Fresh leaves of J. regia were collected from a seedling walnut farm of the Agricul- tural College of Shiraz University and have been identified and confirmed by a faculty member of the Department of Horticultural Science, Agriculture College, Shiraz University (Prof. M. Rahemi), and a voucher specimen of materials (walnut leaves) has been deposited in the herbarium (No. 96WL14). The leaves were dried in shade, and then milled and soaked in ethanol or cyclohexene for 24 hours. After filtration, the solvent was removed by a vacuum distillation machine and the obtained extract was dried in a lyophilizer. The mentioned method was used to obtain other extracts as the instructions in the previous report [32].

2.2. Animals. Fifty-six male Sprague Dawley rats $(200 \pm 20 \mathrm{~g})$ were procured from the Comparative and Experimental Center of Medical Sciences Department of Shiraz Medical University. Rats were maintained in standard temperature $\left(22 \pm 2^{\circ} \mathrm{C}\right)$, moisture (38\%), and light-dark conditions $(12: 12 \mathrm{~h})$, and standard pellet diet and water were provided ad libitum to the animals.

2.3. Animal Ethics. All aspects of animal care and protocols that have been used in this study were in accordance with and approved by the state committee on animal ethics, Shiraz University, Shiraz, Iran. Also, the recommendations of the European Council Directive (86/609/EC) of November 24, 1986, regarding the standards in the protection of animals used for experimental purposes were followed.

2.3.1. Materials. Streptozotocin (N-(methylnitrosocarbamoyl)- $\alpha$-D-glucosamine) was obtained from Sigma Chemical Co., USA, cyclohexane from Merck (KGaA, Germany), ethanol from Haamoon Teb Markazi (Tehran, Iran), Rat Aldose Reductase ELISA Kit from Bioassay Technology Laboratory (Shanghai Crystal Day Biotech Company, LTC, China), and anti-AKR1B1/Aldose Reductase Antibody (aa241-290) IHC plus. All other chemicals and solvents were of analytical grade.

2.3.2. Induction of Diabetes. Diabetes was induced by a single dose of streptozotocin $(60 \mathrm{mg} / \mathrm{kg}$ body weight, intraperitoneal) in citrate buffer $(0.1 \mathrm{M}, \mathrm{pH} 4.5) .72$ hours after STZ injection, by measuring fasting blood glucose levels, diabetes mellitus was confirmed in the animals. Animals with a blood glucose level above $250 \mathrm{mg} / \mathrm{dl}$ were included in the diabetic group [35].

2.4. Experimental Design. The animals were randomly divided into seven equal groups $(n=8)$, according to the following plan, and treated for 30 days by gavage. The selected doses were according to our previous studies $[20,36]$.

Three normal healthy groups were treated as follows:

(1) Control group: received only vehicle (sesame oil)

(2) Treatment control 1: received cyclohexane extract (250 mg/kg/day)

(3) Treatment control 2: received ethanol extract $(250 \mathrm{mg} / \mathrm{kg} / \mathrm{day})$ 
Diabetes mellitus was induced in the next four groups as described above and treated as follows:

(4) Diabetic control: diabetic; received the vehicle

(5) Treatment 1: diabetic; received cyclohexane extract $(250 \mathrm{mg} / \mathrm{kg} / \mathrm{day})$

(6) Treatment 2: diabetic; received ethanol extract $(150 \mathrm{mg} / \mathrm{kg} / \mathrm{day})$

(7) Treatment 3: diabetic; received ethanol extract $(250 \mathrm{mg} / \mathrm{kg} /$ day $)$

2.5. Evaluation of Aldose Reductase Concentration in the Lens and Testis. On the last day of the experiment, rats were anesthetized by $1.9 \%$ diethyl ether-saturated cotton ball in a chamber for 3-5 min and euthanized by whole blood collection through heart puncture. Under the sterile condition, the animal's eye lens was removed and separated from the posterior approach, kept in ice after washing with saline, homogenated in $0.1 \mathrm{M}$ phosphate buffer saline $(\mathrm{pH} 7.4)$, and centrifuged at $15000 \times \mathrm{g}$ for $30 \mathrm{~min}$ at $4^{\circ} \mathrm{C}$. The total protein content of the supernatant was determined according to the method described by Bradford [20].

Aldose reductase was determined using a solid-phase sandwich ELISA method (Rat ELISA Kit; Bioassay Technology Laboratory, Shanghai Crystal Day Biotech Company, LTC, China).

2.6. Immunohistochemical Evaluation of AR Distribution in the Testis. Immunohistochemical analyses of the tissues were carried out based on protocol described by Kieman (1999). In brief, paraffin-embedded tissue sections (3-4 $\mathrm{mm}$ in diameter) were deparaffinized in xylene (three times for ten minutes) and then dehydrated through graded alcohol (100\%, 96\%, and $70 \%$ each of them 20 seconds) and washed with distilled water ( 2 minutes) and washed with phosphate buffer saline (PBS) (5 minutes). Endogenous peroxidase was inactivated in $3 \%$ hydrogen peroxide which stays on the slide for 20 minutes until bubble was observed on the surface of slides and then washed with PBS for 5 minutes. Then, slides were incubated with primary antibody overnight at $4^{\circ} \mathrm{C}$ and washed with PBS 2 times (each of them 10 minutes) and then incubated with Envision for 20-30 minutes and washed with PBS $2 \mathrm{x}$ for 10 minutes Then, slides are incubated in $\mathrm{DAB}$ (3,3'-diaminobenzidine) and washed with PBS or distilled water for 5 minutes; the last step is counterstaining with hematoxylin staining and mounting [37].

2.7. Statistical Analysis. Results are reported as mean \pm SEM. Data were analyzed by SPSS software, version 21.0 for Windows. One-way analysis of variance (ANOVA) followed by post hoc multiple comparisons and Duncan multiple range tests was used to compare mean values between groups, and the significance level was set at $P<0.05$.

\section{Results}

The activity of aldose reductase in the lens of diabetic control was significantly higher than that of the treatment groups

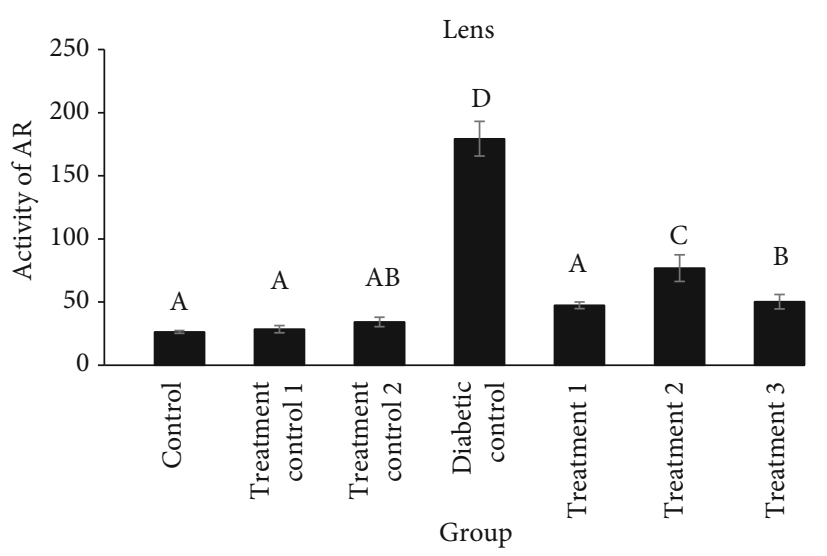

FIGURE 1: Comparison of aldose reductase (AR) activity (unit/mg of tissue protein) in the lens of different groups (mean \pm SEM). Different alphabet letters show significant differences between groups.

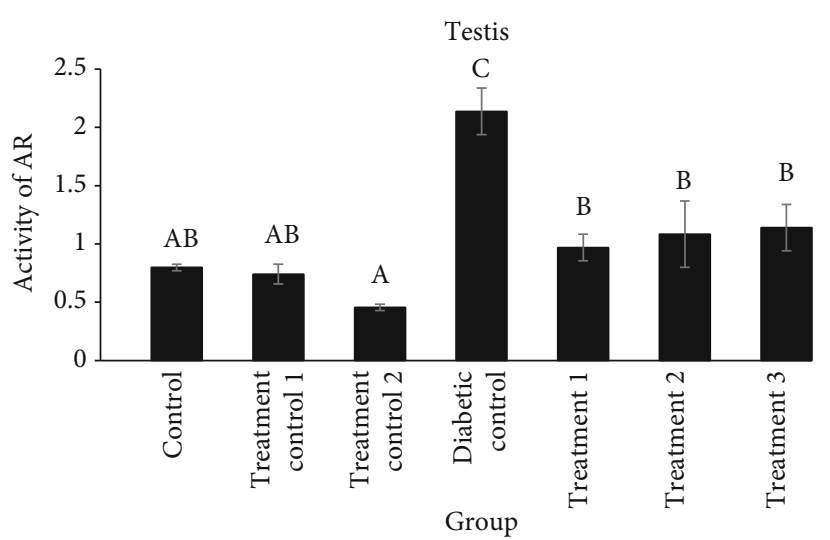

FIGURE 2: Comparison of aldose reductase (AR) activity (unit/mg of tissue protein) in the testis of different groups (mean \pm SEM). Different alphabet letters show significant differences between groups.

$(P<0.0001)$. Aldose reductase activity in the testis of the diabetic control group was significantly higher than that of the other groups, and treatment with cyclohexane or ethanol extracts decreased its activity significantly compared to the diabetic control groups (compared to treatment 1 $(P=0.0004)$, treatment $2(P=0.0032)$, and treatment 3 $(P=0.0026))$ (Figures 1 and 2$)$.

3.1. Distribution of AR in Rat Testis. The distribution of AR in the testis in different groups which was obtained by the immunohistochemical study is shown in Figure 3. The distribution of AR increases significantly in the diabetic control group compared to other groups $(P<0.0001)$, which is shown as a decrease in color intensity in Figures 3 and 4.

\section{Discussion}

Status of glycemic control and the duration of diabetes are important risk factors in the formation of diabetic cataracts $[38,39]$. Several hypotheses have been proposed in the 


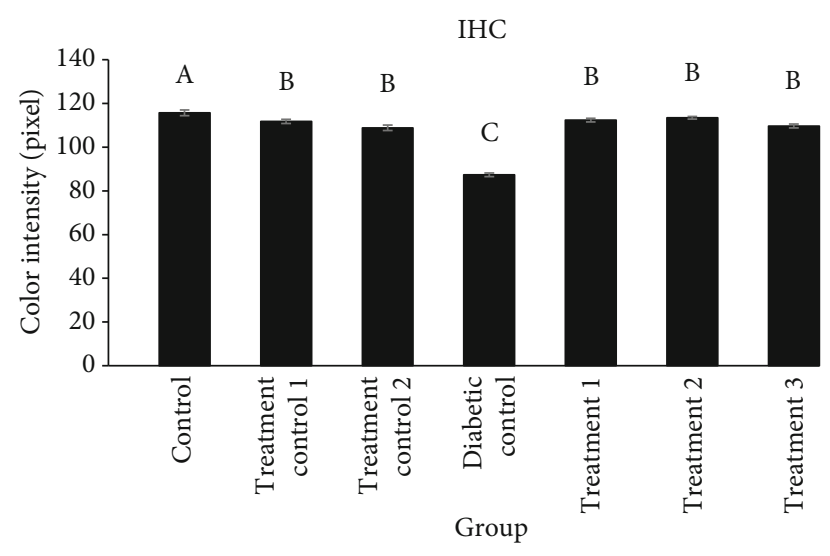

FIGURE 3: Comparison of the distribution of aldose reductase in the testis in different groups (mean \pm SEM). Different alphabet letters show significant differences between groups.

pathogenesis of diabetic cataracts, but the activation of PPW and its enzyme AR is of great concern [40].

As was mentioned in Results, walnut leaf extracts decreased the activity and localization of AR in the testes of diabetic rats and also reduced AR activity in the lens of diabetic rats. Plants are rich sources of phytochemicals such as flavonoids and polyphenols which may act as aldose reductase inhibitors [41]. Similar results were reported using cinnamon extract on the activity of aldose reductase of the lens in the in vitro condition and also using Zea mays $[41,42]$.

Both oxidants and a high level of serum glucose can activate extracellular signal-regulated kinases (ERK) and JNK (c-Jun N-terminal kinases) [43]. ERK activation in the lens may be the cause of the development of cataracts by upregulating GLUT-1, which increases the uptake of glucose for the PPW $[44,45]$.

It has been reported that hyperglycemia-induced oxidative stresses activate JNK, causing apoptosis in human endothelial cells. JNK activation and hyperglycemia-induced apoptosis were reported to decrease, respectively, by the administration of vitamin C (as an antioxidant) [46].

Oxidative stress and mitochondrial dysfunction are important features of metabolic disorders, and hyperglycemia can evoke a mitochondrial overload in tissues with a high rate of energy metabolism, resulting in increased mitochondrial respiratory chain activity and oxidative stress [6].

During hyperglycemia, the balance between production and elimination of free radicals is also disrupted. As a result, free radicals increase and cause oxidative stress. Oxidative stress causes cell damage through mechanisms such as lipid peroxidation and DNA and protein oxidative damage in the tissues [47]. Moreover, oxidative species promote the glycoxidation reaction of proteins in the presence of reducing sugars, thus resulting in AGE accumulation.

It has been proven that the PPW is the primary mediator of diabetes-induced oxidative stress in the lens [48]. Researchers have focused on the first step of the PPW as initiating factors in diabetic cataract formation, which occur due to the accumulation of sorbitol-induced stress as osmotic stress in the endoplasmic reticulum (ER), the main site of protein synthesis, leading to the generation of free radicals. The stress of ER may be due to glucose level disturbance initiating an unfolded protein response which causes oxidative stress damage to lens fibers $[49,50]$.

A high level of glucose in the aqueous humor may cause glycation of lens protein, resulting in the formation of superoxide radicals $\left(\mathrm{O}^{-2}\right)$ [51].

It has been shown that in diabetic rats, flavonoids such as quercetin or isoflavone genistein delayed the formation of diabetic cataracts $[52,53]$. Also, the treatment of diabetic rats with ginger significantly inhibited the formation of various AGE products, including carboxymethyl lysine in the lens, and delayed the progression and onset of cataract [54]. Moreover, a combination of vitamin E, a lipid-soluble and antioxidant vitamin, and insulin could prevent the formation and progression of cataracts in the animals [55].

The walnut leaf extract contains ingredients such as quercetin, kaempferol, eugenol, avicularin, nicotine, caffeic acid, hyperin, beta-eudesmol, juglone, p-Coumaric acid, ascorbic acid, ellagic acid, gallic acid, neochlorogenic acid, and cyaniding, while quercetin and kaempferol are possibly major active ingredients $[56,57]$.

Although the PPW causes oxidative stress in both the lens and the nerve, its role in the development of diabetic lesions in these two tissues seems to be different. The activation of AR in the PPW can lead to the alteration of various metabolic factors, particularly the formation of ROS which leads to oxidative stress, as the initial and main inducing factor of cataract [16].

The present study showed that oral administration of different doses of cyclohexane and ethanol extracts of the walnut leaf decreases the activity of AR in all of the diabetic treated rats compared with the diabetic control group significantly. This reduction was more obvious in the lens of diabetic treatment 1 compared to diabetic treatments 2 and 3. It can be suggested that the action of antioxidants present in the walnut leaves [36] improves the activity of AR in the diabetic groups. The results of this study are consistent with the results obtained by Yoshida et al. and Goodarzi et al. $[55,58]$, and it can be concluded that the antioxidants and quercetin in the walnut leaf may be effective in reducing the activity of the aldose reductase. A decrease in the activity of $\mathrm{AR}$ in the lens was also reported using cinnamon extract in in vitro condition [41].

Our results showed that oral administration of different doses of cyclohexane and ethanol extracts in the diabetic groups decreases the aldose reductase activity and its distribution in the testicular tissue compared to the diabetic control group.

Hyperglycemia-induced oxidative stress has been proposed as an important factor affecting reproductive function by excessive generation of reactive oxygen species (ROS). A decrease in enzymes involved in reducing ROS in the testis tissue of diabetic rats has been reported, and treatment with Galega officinalis extract was reported to improve oxidative stress and tissue damage [24]. Oxidative stress causes cell damage through mechanisms such as destruction in the endothelium of tubule and apoptosis in the testicular germ 


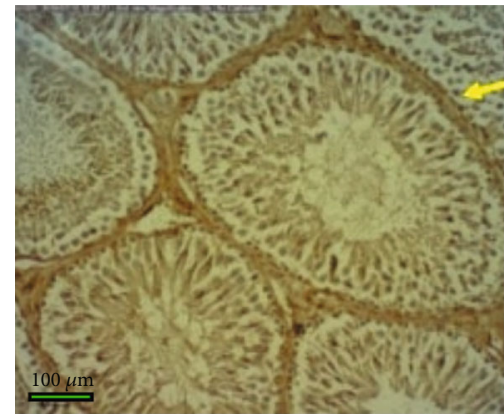

(a)

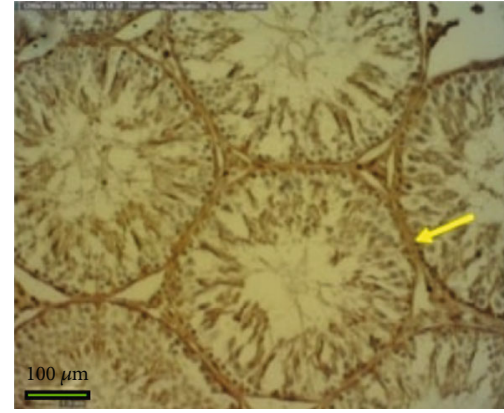

(c)

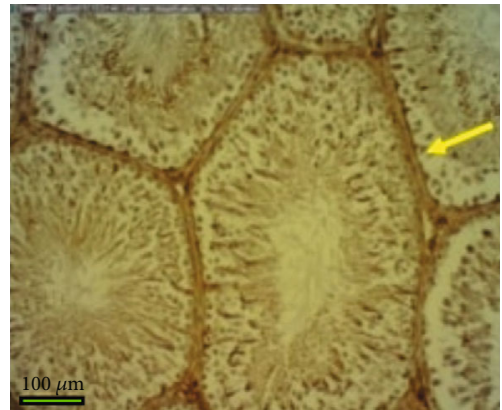

(e)

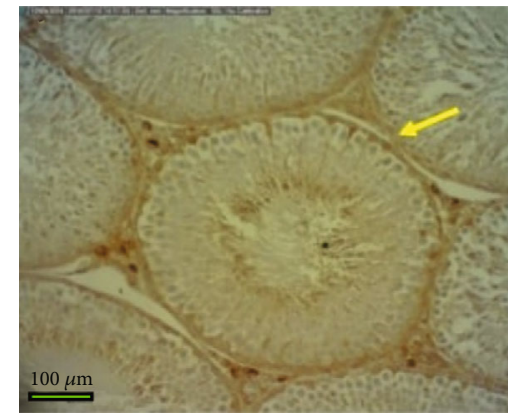

(b)

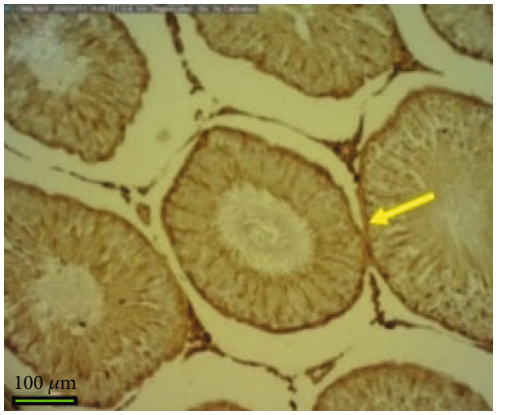

(d)

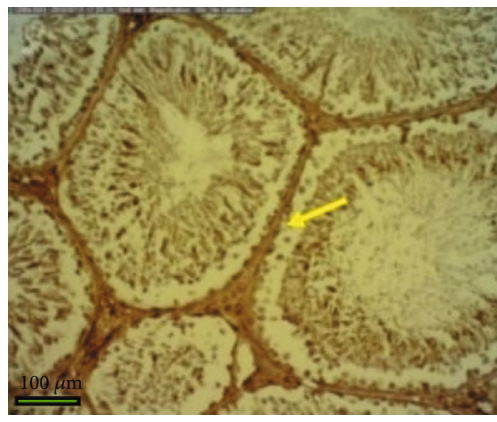

(f)

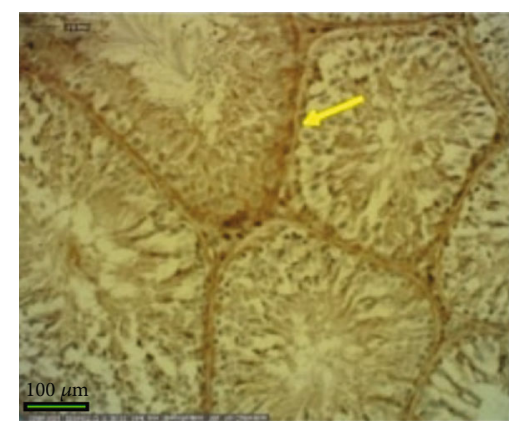

(g)

FIgURE 4: Immunohistochemical localization of aldose reductase in the sections of the testis in different groups: (a) control group; (b) treatment control 1; (c) treatment control 2; (d) diabetic control; (e) treatment 1; (f) treatment 2; (g) treatment 3. Bars =100 $\mu \mathrm{m}$. Magnification: $\times 10$.

cell, lipid peroxidation, and DNA and protein oxidative damage in the tissues [25].

Because of the high concentration of steroid in the male reproductive system, it is exposed to oxidative stress caused by high metabolism activity, which results in a high concentration of reducing sugars $[59,60]$. At a particular stage, increased cell death in germ cells has been observed in the seminiferous tubules of diabetic animals [61].

It has been suggested that the strong antioxidant activity of flavonoids present in plants can play a protective role against diseases caused by oxidative stress, and recent attention has focused on the use of flavonoids to prevent and treat 
the diseases $[62,63]$. Therefore, the effect of walnut leaf extracts on the distribution of aldose reductase in testicular tissue could be due to its flavonoid's effect on the PPW route and ultimately on oxidative stress.

Considering the inhibitory effects of other plants such as tea leaves [64], Zingiber officinale [65], and Phyllostachys nigra [66] on aldose reductase, the antioxidant properties of walnut leaves, and our finding regarding the decrease of aldose reductase activity and distribution in the testicular tissue of the treatment groups, it can be proposed that the flavonoid antioxidants of walnut leaves can reduce diabetic oxidative stress through alteration of the polyol pathway, which may prevent or delay some of the important complications of diabetes mellitus. This finding may confirm other reports for the use of antidiabetic plants to ameliorate complications in diabetic patients.

\section{Conclusion}

It can be concluded that walnut leaf extracts can reduce the activity and localization of $\mathrm{AR}$ in the testes of diabetic rats and also reduce AR activity in the lens of diabetic rats. This finding was confirmed by the evaluation of enzyme activity in the lens and testis and its distribution in the testis by immunohistochemical study. However, further studies are needed to establish these effects in other species or doses to be applicable in human beings.

5.1. Study Limitations and Suggestions. Other biological methods to evaluate the expression of $\mathrm{AR}$ and $\mathrm{SDH}$ in the tissue are useful, but due to budget limitation, we were not able to do so in the current study.

\section{Data Availability}

All the data generated in this current work are included in Results and Discussion. Raw data supporting the findings of the current work are available from the corresponding author on reasonable request. A voucher specimen of walnut leaves has been deposited in the herbarium.

\section{Ethical Approval}

All aspects of animal care and protocols that have been used in this study were in accordance with and approved by the state committee on animal ethics, Shiraz University, Shiraz, Iran. Also, the recommendations of the European Council Directive (86/609/EC) of November 24, 1986, regarding the standards in the protection of animals used for experimental purposes were followed.

\section{Conflicts of Interest}

The authors declare that they have no conflicts of interest to be mentioned.

\section{Acknowledgments}

We acknowledge Prof. Majid Rahemi, a faculty member of the Department of Horticultural Science, College of Agricul- ture, Shiraz University, for his assistance in identifying and providing walnut leaf.

\section{References}

[1] I. M. Agbaje, D. A. Rogers, C. M. McVicar et al., "Insulin dependant diabetes mellitus: implications for male reproductive function," Human Reproduction, vol. 22, no. 7, pp. 1871-1877, 2007.

[2] S. A. Paschou, N. Papadopoulou-Marketou, G. P. Chrousos, and C. Kanaka-Gantenbein, "On type 1 diabetes mellitus pathogenesis,” Endocrine Connections, vol. 7, no. 1, pp. R38-R46, 2018.

[3] M. Saraswat, P. Muthenna, P. Suryanarayana, J. M. Petrash, and G. B. Reddy, "Dietary sources of aldose reductase inhibitors: prospects for alleviating diabetic complications," Asia Pacific Journal of Clinical Nutrition, vol. 17, no. 4, pp. 558565, 2008.

[4] A. Bhatnagar and S. K. Srivastava, "Aldose reductase: congenial and injurious profiles of an enigmatic enzyme," Biochemical Medicine and Metabolic Biology, vol. 48, no. 2, pp. 91-121, 1992.

[5] M. Brownlee, "Biochemistry and molecular cell biology of diabetic complications," Nature, vol. 414, no. 6865, pp. 813-820, 2001, Epub 2001/12/14. eng.

[6] M. Aragno and R. Mastrocola, "Dietary sugars and endogenous formation of advanced glycation endproducts: emerging mechanisms of disease," Nutrients, vol. 9, no. 4, p. 385, 2017.

[7] T. T. Turner and J. J. Lysiak, "Oxidative stress: a common factor in testicular dysfunction," Journal of Andrology, vol. 29, no. 5, pp. 488-498, 2008.

[8] R. J. Aitken, "Reactive oxygen species as mediators of sperm capacitation and pathological damage," Molecular Reproduction and Development, vol. 84, no. 10, pp. 1039-1052, 2017.

[9] M. Soltani, M. Moghimian, S. H. Abtahi-Eivari, H. Shoorei, A. Khaki, and M. Shokoohi, "Protective effects of matricaria chamomilla extract on torsion/detorsion-induced tissue damage and oxidative stress in adult rat testis," International Journal of Fertility \& Sterility, vol. 12, no. 3, pp. 242-248, 2018.

[10] M. Shokoohi, A. Khaki, H. Shoorei, A. A. Khaki, M. Moghimian, and S.-. H. Abtahi-Eivary, "Hesperidin attenuated apoptotic-related genes in testicle of a male rat model of varicocoele," Andrology, vol. 8, no. 1, pp. 249-258, 2019.

[11] M. Kernt, C. Hirneiss, A. S. Neubauer, M. W. Ulbig, and A. Kampik, "Coenzyme Q10 prevents human lens epithelial cells from light-induced apoptotic cell death by reducing oxidative stress and stabilizing BAX / Bcl-2 ratio," Acta Ophthalmologica, vol. 88, no. 3, pp. e78-e86, 2010, Epub 2010/04/09. eng.

[12] Z. Huang, J. Jiang, V. A. Tyurin et al., "Cardiolipin deficiency leads to decreased cardiolipin peroxidation and increased resistance of cells to apoptosis," Free Radical Biology \& Medicine, vol. 44, no. 11, pp. 1935-1944, 2008, Epub 2008/04/01. eng.

[13] L. Huang, M. C. Yappert, M. M. Jumblatt, and D. Borchman, "Hyperoxia and thyroxine treatment and the relationships between reactive oxygen species generation, mitochondrial membrane potential, and cardiolipin in human lens epithelial cell cultures," Current Eye Research, vol. 33, no. 7, pp. 575586, 2009. 
[14] R. J. W. Truscott, "Age-related nuclear cataract-oxidation is the key," Experimental Eye Research, vol. 80, no. 5, pp. 709725, 2005, Epub 2005/05/03. eng.

[15] V. Bantseev, D. McCanna, A. Banh et al., "Mechanisms of ocular toxicity using the in vitro bovine lens and sodium dodecyl sulfate as a chemical model," Toxicological Sciences, vol. 73, no. 1, pp. 98-107, 2003, Epub 2003/04/18. eng.

[16] A. Y. W. Lee and S. S. M. Chung, "Contributions of polyol pathway to oxidative stress in diabetic cataract," The FASEB journal, vol. 13, no. 1, pp. 23-30, 1999, Epub 1999/01/05. eng.

[17] A. Snow, B. Shieh, K.-C. Chang et al., "Aldose reductase expression as a risk factor for cataract," Chemico-biological Interactions, vol. 234, pp. 247-253, 2015.

[18] A. B. M. Reddy, R. Tammali, R. Mishra, S. Srivastava, S. K. Srivastava, and K. V. Ramana, "Aldose reductase deficiency protects sugar-induced lens opacification in rats," ChemicoBiological Interactions, vol. 191, no. 1-3, pp. 346-350, 2011.

[19] P. F. Kador, G. Sun, V. K. Rait, L. Rodriguez, Y. Ma, and K. Sugiyama, "Intrinsic inhibition of aldose reductase," Journal of Ocular Pharmacology and Therapeutics, vol. 17, no. 4, pp. 373-381, 2001.

[20] Z. Abbasi, G. Jelodar, and S. Nazifi, "Extracts of the walnut leaf (Juglans regia L.) improved activity of sorbitol dehydrogenase in diabetic male rats," Physiology and Pharmacology, vol. 21, no. 1, pp. 80-86, 2017.

[21] N. Halder, S. Joshi, and S. K. Gupta, "Lens aldose reductase inhibiting potential of some indigenous plants," Journal of Ethnopharmacology, vol. 86, no. 1, pp. 113-116, 2003, Epub 2003/04/11. eng.

[22] C. S. Kim, J. Kim, Y. M. Lee, E. Sohn, and J. S. Kim, "Esculetin, a coumarin derivative, inhibits aldose reductase activity in vitro and cataractogenesis in galactose-fed rats," Biomolecules \& Therapeutics, vol. 24, no. 2, pp. 178-183, 2016, Epub 2016/02/24. eng.

[23] R. Rahimi, S. Nikfar, B. Larijani, and M. Abdollahi, "A review on the role of antioxidants in the management of diabetes and its complications," Biomedicine \& Pharmacotherapy, vol. 59, no. 7, pp. 365-373, 2005, Epub 2005/08/06. eng.

[24] F. Shokri, M. Shokoohi, H. R. Niazkar, A. R. R. Abadi, H. Kalarestaghi, and M. Ahin, "Investigation the spermatogenesis and testis structure in diabetic rats after treatment with galega officinalis extract," Crescent Journal of Medical and Biological Sciences., vol. 6, no. 1, pp. 31-36, 2019.

[25] E. Yuluğ, S. Türedi, E. Karagüzel, Ö. Kutlu, A. Menteşe, and A. Alver, "The short term effects of resveratrol on ischemiareperfusion injury in rat testis," Journal of Pediatric Surgery, vol. 49, no. 3, pp. 484-489, 2014.

[26] T. Fukuda, H. Ito, and T. Yoshida, "Effect of the walnut polyphenol fraction on oxidative stress in type 2 diabetes mice," BioFactors, vol. 21, no. 1-4, pp. 251-253, 2004, Epub 2005/01/05. eng.

[27] X. Tang and D. A. Cronin, "The effects of brined onion extracts on lipid oxidation and sensory quality in refrigerated cooked turkey breast rolls during storage," Food Chemistry, vol. 100, no. 2, pp. 712-718, 2007.

[28] H. S. Yang, E. J. Lee, S. H. Moon, H. D. Paik, K. Nam, and D. U. Ahn, "Effect of garlic, onion, and their combination on the quality and sensory characteristics of irradiated raw ground beef," Animal Industry Report, vol. 89, no. 2, pp. 202-208, 2011.

[29] A. Jang, X.-D. Liu, M.-H. Shin et al., “Antioxidative potential of raw breast meat from broiler chicks fed a dietary medicinal herb extract mix," Poultry Science, vol. 87, no. 11, pp. 2382 2389, 2008.

[30] M. Metwally, "Effects of garlic (Allium sativum) on some antioxidant activities in tilapia nilotica (Oreochromis niloticus)," World Journal of Fish and Marine Sciences, vol. 1, no. 1, pp. 56-64, 2009.

[31] K. Kumari and K. T. Augusti, "Lipid lowering effect of S -methyl cysteine sulfoxide from Allium cepa Linn in high cholesterol diet fed rats," Journal of Ethnopharmacology, vol. 109, no. 3, pp. 367-371, 2007.

[32] G. Jelodar and S. Nazifi, "Effect of walnut leaf extracts on serum biochemical parameters of diabetic rats," Journal of Veterinary Faculty, University of Tehran, vol. 56, no. 2, pp. 37-40, 2001.

[33] R. E. Dzhafarova, G. Garaev, and Z. S. Dzhafarkulieva, "Antidiabetic action of extract of Juglans regia L," Georgian Medical News, vol. 170, pp. 110-114, 2009.

[34] J. A. Pereira, I. Oliveira, A. Sousa et al., "Walnut ( Juglans regia L.) leaves: Phenolic compounds, antibacterial activity and antioxidant potential of different cultivars," Food and Chemical Toxicology, vol. 45, no. 11, pp. 2287-2295, 2007, Epub 2007/07/20. eng.

[35] S. M. Mazloomi, S. Shekarforoush, and J. Sajedianfard, "Effect of synbiotic yogurt on blood biochemical parameters in streptozotocin-induced diabetic rats," Online Journal of Veterinary Research, vol. 14, pp. 66-74, 2010.

[36] G. Jelodar, M. Mohammadi, A. Akbari, and S. Nazifi, "Cyclohexane extract of walnut leaves improves indices of oxidative stress, total homocysteine and lipids profiles in streptozotocin-induced diabetic rats," Physiological Reports, vol. 8, article e14348, 2020.

[37] J. A. Kiernan, "Histological and Histochemical Methods: Theory and Practice, 3rd Edition," Shock, vol. 12, no. 6, p. 479, 1999.

[38] S. I. Kim and S. J. Kim, "Prevalence and risk factors for cataracts in persons with type 2 diabetes mellitus," Korean Journal of Ophthalmology, vol. 20, no. 4, pp. 201-204, 2006.

[39] A. Pollreisz and U. Schmidt-Erfurth, "Diabetic Cataract-Pathogenesis, Epidemiology and Treatment," Journal of Ophthalmology, vol. 2010, Article ID 608751, 8 pages, 2010.

[40] C. Yabe-Nishimura, "Aldose reductase in glucose toxicity: a potential target for the prevention of diabetic complications," Pharmacological Reviews, vol. 50, no. 1, pp. 21-33, 1998.

[41] H.-S. Lee, "Inhibitory activity of Cinnamomum cassia barkderived component against rat lens aldose reductase," Journal of Pharmacy \& Pharmaceutical Sciences, vol. 5, no. 3, pp. 226230, 2002.

[42] T. H. Kim, J. K. Kim, Y.-H. Kang, J.-Y. Lee, I. J. Kang, and S. S. Lim, "Aldose reductase inhibitory activity of compounds from Zea mays L," BioMed Research International, vol. 2013, Article ID 727143, 2013.

[43] M. George, E. Ayuso, A. Casellas, C. Costa, J. C. Devedjian, and F. Bosch, "Beta cell expression of IGF-I leads to recovery from type 1 diabetes," The Journal of Clinical Investigation, vol. 109, no. 9, pp. 1153-1163, 2002, Epub 2002/05/08. eng.

[44] X. Gong, X. Wang, J. Han, I. Niesman, Q. Huang, and J. Horwitz, "Development of cataractous macrophthalmia in mice expressing an active MEK1 in the lens," Investigative Ophthalmology \& Visual Science, vol. 42, no. 3, pp. 539-548, 2001, Epub 2001/02/27. eng. 
[45] D. S. Zatechka, P. F. Kador, S. Garcia-Castineiras, and M. F. Lou, "Diabetes can alter the signal transduction pathways in the lens of rats," Diabetes, vol. 52, no. 4, pp. 1014-1022, 2003.

[46] J. L. Evans, I. D. Goldfine, B. A. Maddux, and G. M. Grodsky, "Oxidative stress and stress-activated signaling pathways: a unifying hypothesis of type 2 diabetes," Endocrine Reviews, vol. 23, no. 5, pp. 599-622, 2002, Epub 2002/10/10. eng.

[47] K. Tremellen, "Oxidative stress and male infertility-a clinical perspective," Human Reproduction Update, vol. 14, no. 3, pp. 243-258, 2008.

[48] J. H. Kinoshita, "Mechanisms initiating cataract formation. Proctor lecture," Investigative Ophthalmology, vol. 13, no. 10, pp. 713-724, 1974, Epub 1974/10/01. eng.

[49] R. Elanchezhian, P. Palsamy, C. J. Madson et al., "Low glucose under hypoxic conditions induces unfolded protein response and produces reactive oxygen species in lens epithelial cells," Cell Death \& Disease, vol. 3, no. 4, article e301, 2012Epub 2012/04/20. eng.

[50] M. L. Mulhern, C. J. Madson, A. Danford, K. Ikesugi, P. F. Kador, and T. Shinohara, "The unfolded protein response in lens epithelial cells from galactosemic rat lenses," Investigative ophthalmology \& visual science., vol. 47, no. 9, pp. 3951-3959, 2006, Epub 2006/08/29. eng.

[51] A. W. Stitt, "The maillard reaction in eye diseases," Annals of the New York Academy of Sciences., vol. 1043, no. 1, pp. 582597, 2005, Epub 2005/07/23. eng.

[52] S. D. Varma, A. Mizuno, and J. H. Kinoshita, "Diabetic cataracts and flavonoids," Science, vol. 195 , no. 4274, pp. 205206, 1977, Epub 1977/01/14. eng.

[53] S. D. Varma, S. S. Schocket, and R. D. Richards, "Implications of aldose reductase in cataracts in human diabetes," Investigative Ophthalmology \& Visual Science, vol. 18, no. 3, pp. 237241, 1979.

[54] M. Saraswat, P. Suryanarayana, P. Y. Reddy, M. A. Patil, N. Balakrishna, and G. B. Reddy, "Antiglycating potential of Zingiber officinalis and delay of diabetic cataract in rats," Molecular Vision, vol. 16, p. 1525, 2010.

[55] M. Yoshida, H. Kimura, K. Kyuki, and M. Ito, "Combined effect of vitamin $\mathrm{E}$ and insulin on cataracts of diabetic rats fed a high cholesterol diet," Biological \& Pharmaceutical Bulletin, vol. 27, no. 3, pp. 338-344, 2004, Epub 2004/03/03. eng.

[56] H. Madani, P. Rahimi, and P. Mahzoni, "Effects of hydroalcoholic extract of Juglans regia leaves on activity of AST and ALT enzymes in alloxan- induced diabetic rats," Pharmaceutical Sciences, vol. 15, pp. 213-218, 2009.

[57] M. Blumenthal, A. Goldberg, and J. Brinckmann, Herbal Medicine. Expanded Commission E Monographs: Integrative Medicine Communications, Integrative Medicine communication, Newton, MA. USA, 2000.

[58] M. Goodarzi, F. Zal, M. Malakooti, M. Safari, and S. Sadeghian, "Inhibitory activity of flavonoids on the lens aldose reductase of healthy and diabetic rats," Acta Medica Iranica, vol. 44, no. 1, pp. 41-45, 2006.

[59] A.-M. Lefrançois-Martinez, C. Tournaire, A. Martinez et al., "Product of side-chain cleavage of cholesterol, isocaproaldehyde, is an endogenous specific substrate of mouse vas deferens protein, an aldose reductase-like protein in adrenocortical cells," The Journal of Biological Chemistry, vol. 274, no. 46, pp. 32875-32880, 1999, Epub 1999/11/07. eng.

[60] N. Nishi, H. Shoji, H. Miyanaka, and T. Nakamura, “Androgen-regulated expression of a novel member of the aldo-keto reductase superfamily in regrowing rat prostate," Endocrinology, vol. 141, no. 9, pp. 3194-3199, 2000.

[61] S. Sainio-Pöllänen, K. Henriksen, M. Parvinen, O. Simell, and P. Pöllänen, "Stage-specific degeneration of germ cells in the seminiferous tubules of non-obese diabetic mice," International Journal of Andrology, vol. 20, no. 4, pp. 243-254, 1997.

[62] Y.-X. Lu, Q. Zhang, J. Li et al., “Antidiabetic effects of total flavonoids from Litsea Coreana leve on fat-fed, streptozotocininduced type 2 diabetic rats," The American Journal of Chinese Medicine, vol. 38, no. 4, pp. 713-725, 2012.

[63] M. Mirshekar, M. Roghani, M. Khalili, T. Baluchnejadmojarad, and S. A. Moazzen, "Chronic oral pelargonidin alleviates streptozotocin-induced diabetic neuropathic hyperalgesia in rat: involvement of oxidative stress," Iranian Biomedical Journal, vol. 14 , no. $1-2$, pp. 33-39, 2010 .

[64] I. Sakai, S. I. Izumi, T. Murano, S. Okuwaki, T. Makino, and T. Suzuki, "Presence of aldose reductase inhibitors in tea leaves," Japanese Journal of Pharmacology, vol. 85, no. 3, pp. 322-326, 2001, Epub 2001/04/28. eng.

[65] A. Kato, Y. Higuchi, H. Goto et al., "Inhibitory effects of Zingiber officinale Roscoe derived components on aldose reductase activity in vitro and in vivo," Journal of Agricultural and Food Chemistry, vol. 54, no. 18, pp. 6640-6644, 2006, Epub 2006/08/31. eng.

[66] S. H. Jung, J. M. Lee, H. J. Lee, C. Y. Kim, E. H. Lee, and B. H. Um, "Aldose reductase and advanced glycation endproducts inhibitory effect of Phyllostachys nigra," Biological \& Pharmaceutical Bulletin, vol. 30, no. 8, pp. 1569-1572, 2007, Epub 2007/08/02. eng. 